Regul at ory B cel I s in ski $n$ and connect i ve ti ssue di seases

\begin{tabular}{|l|l|}
\hline 著者 & Fuj i not o Nanabu \\
\hline $\begin{array}{l}\text { j our nal or } \\
\text { publ i cat i on ti t l e }\end{array}$ & Journal of Der nat ol ogi cal Sci ence \\
\hline vol une & 60 \\
\hline number & 1 \\
\hline page r ange & $1-7$ \\
\hline year & $2010-10-01$ \\
\hline URL & ht t p: //hdl . handl e. net /2297/25437 \\
\hline
\end{tabular}


Review article

\section{Regulatory B cells in skin and connective tissue diseases}

Manabu Fujimoto

Department of Dermatology, Kanazawa University Graduate School of Medical Science

Running title: Regulatory B cells

Key words: regulatory B cell, B10 cell, IL-10, contact hypersensitivity, systemic lupus erythematosus

Correspondence: Manabu Fujimoto, M.D., Department of Dermatology, Kanazawa University Graduate School of Medical Science, 13-1 Takaramachi, Kanazawa, Ishikawa 920-8641, Japan.

Phone: 81-76-265-2341

Fax: 81-76-234-4270

E-mail: fujimoto-m@umin.ac.jp 


\section{Summary}

While B cells are generally considered to be positive regulators of humoral immune responses due to their ability to differentiate into plasmablasts/plasma cells and produce antibodies, B cells also modulate immune responses through antigen presentation and cytokine secretion. Moreover, "regulatory B cells" that suppress immune responses have been recognized as an important new component of the immune system. In mice, the function of regulatory B cells is almost exclusively dependent on IL-10. The cell surface phenotype of murine IL-10-producing regulatory B cells is reported to be CD1d ${ }^{\text {hi }} \mathrm{CD}^{+}{ }^{\text {or }} \mathrm{CD} 1 \mathrm{~d}^{\mathrm{hi}} \mathrm{CD} 21^{\mathrm{hi}} \mathrm{CD} 23^{+}$IgM $^{\mathrm{hi}}$, and thus their phenotype overlaps with that of $\mathrm{CD}^{+}$B-1a cells, CD1d ${ }^{\text {hi }} \mathrm{CD} 21^{\text {hi }} \mathrm{CD} 23^{\mathrm{lo}} \mathrm{IgM}^{\text {hi }}$ marginal zone (MZ) B cells, and CD1d ${ }^{\text {hi }} C D 21^{\text {hi }} C D 23^{\text {hi }}$ IgM $^{\text {hi }}$ T2-MZ precursor B cells. Contrary to earlier work that suggested a minor role for B cells in contact hypersensitivity, regulatory B cells are now known to have a critical inhibitory functions in this type of immune response. Furthermore, studies using murine disease models have demonstrated that regulatory B cells play a significant role in autoimmune connective tissue diseases such as rheumatoid arthritis and systemic lupus erythematosus, as well as organ-specific autoimmune diseases including experimental autoimmune encephalomyelitis and inflammatory bowel disease. In comparison to mouse regulatory B cells, little is known regarding their human counterparts. One recent study demonstrates that human $\mathrm{CD} 19^{+} \mathrm{CD} 24^{\text {hi }} \mathrm{CD} 38^{\mathrm{hi}} \mathrm{B}$ cells possess regulatory capacity. Clarifying the molecular mechanisms by which regulatory B cells suppress immune responses will be of great benefit in the development of new B cell-targeted therapeutic strategies. 


\section{Introduction}

Optimal immune responses are accomplished by balancing the function of "activating” subsets and "suppressive" subsets of immune cells. This is most clearly understood for $\mathrm{T}$ cells, in which effector $\mathrm{T}$ cells and regulatory $\mathrm{T}$ cells have opposing roles in maintaining the delicate balance between host defense, inflammation, and autoimmunity.

Historically, B cells have been characterized as positive regulators of humoral immune responses by their ability to differentiate into plasmablasts/plasma cells and produce antibodies (Abs). Nonetheless, B-cell suppression of an immune response was first described back in 1974 where splenic B cells were found to impair delayed type hypersensitivity (DTH) responses in guinea pigs [1]. Recently, however, B cell subsets that suppress immune responses, termed “regulatory B cells”, have been recognized as an important new component of the immune system [2-5]. Studies have demonstrated that regulatory B cells play a major role in various immune responses and diseases, from simple contact hypersensitivity to complex systemic autoimmune diseases, and that the suppression mediated by regulatory B cells is an important means not only for the termination of inflammation but also for the maintenance of peripheral tolerance. Identification of the molecular mechanisms underlying regulatory B cell suppression of immune responses is of great relevance in the understanding of allergic skin diseases and autoimmune diseases, and in the development of new therapeutic strategies.

\section{Various functions of $B$ cells}

B cells are classified into two lineages, B-1 and B-2 cells. B-1 cells emerge early in development and are abundantly present in the peritoneal and pleural cavities, and are defined by the following pattern of surface marker expression: $\mathrm{B}_{22}{ }^{\mathrm{lo}}, \operatorname{IgM}^{\mathrm{hi}}$, IgD ${ }^{+}$, $\mathrm{CD}^{+}, \mathrm{CD}_{4}{ }^{+}$, and $\mathrm{CD} 23^{\mathrm{lo}}$. B-2 cells are defined phenotypically as B220 ${ }^{\mathrm{hi}}, \operatorname{IgM}^{\mathrm{hi} / \mathrm{lo}}$, $\mathrm{IgD}^{+}, \mathrm{CD}^{-}, \mathrm{CD}^{-} 3^{-}$, and $\mathrm{CD} 23^{\mathrm{hi}}$. B-1a cells express CD5, while the B-1b subset does 
not. B-1 cells are long-lived, self-renewing cells that produce polyreactive IgM known as natural Abs, and do not undergo extensive somatic hypermutation. B-2 cells, in contrast, are capable of generating hypermutated Abs, and take the central role in the conventional adaptive humoral immunity. Immature B-2 cells develop in the bone marrow and migrate to the spleen, and are then called transitional B cells (Figure 1). Transitional B cells can be further subdivided into two populations, T1 $\left(\operatorname{IgD}^{-} \operatorname{IgM}^{+} \mathrm{CD} 21^{\mathrm{lo}} \mathrm{CD} 23^{-}\right)$and T2 $\left(\operatorname{IgD}^{\mathrm{hi}} \operatorname{IgM}^{\mathrm{hi}} \mathrm{CD} 21^{\mathrm{int}} \mathrm{CD} 23^{+}\right)$. An additional transitional B cell subset termed T3 has been reported, although T3 cells may be anergic, rather than precursors of mature, B cells. Transitional B cells maturate into follicular B cells $\left(\operatorname{IgD}^{\text {hi }} \operatorname{IgM}^{\mathrm{lo}} \mathrm{CD} 21^{\mathrm{int}} \mathrm{CD} 23^{\mathrm{hi}}\right)$ or marginal zone (MZ) B cells $\left(\operatorname{IgM}^{\mathrm{hi}} \operatorname{IgD}^{\mathrm{lo}} \mathrm{CD} 21^{\mathrm{hi}} \mathrm{CD} 1 \mathrm{~d}^{\mathrm{hi}} \mathrm{CD} 23^{\mathrm{lo}}\right)$. Naive follicular B cells encounter antigens (Ags) in the secondary lymphoid organs and, in conjunction with cognate T-cell help, become activated and proliferate. Activated B cells differentiate into memory B cells or plasma cells. In contrast, MZ B cells, another B-2 cell subset, are specialized to reside in the splenic marginal sinus, a compartment that samples the blood stream for pathogens. B-1 and MZ B cells both play important role in the rapid response of the immune system to pathogens in the blood as well as the peritoneal and pleural cavities.

While the hallmark function of B cells is Ab production, B cells have many other functions including an ability to serve as antigen presenting cells (APSs) [6-9]. B cells are able to internalize immune complexes, present Ag via class II MHC and express co-stimulatory molecules, such as CD80, CD86, and OX40L. B cells can also produce cytokines in response to a diverse array of stimuli, including microbial products, Ags, cytokines, and T cells [10]. The cytokines produced by B cells include interferon (IFN)- $\gamma$, interleukin (IL)-4, IL-10, and IL-12. These cytokine-producing effector B cells are able to promote the differentiation of naive $\mathrm{T}$ cells into Th1/Th2 effectors [11]. Furthermore, B cells can influence the Ag-presenting functions of dendritic cells (DCs). Thus, in addition to their classic role of producing Abs, B cells can positively regulate 
immune responses in a multiude of ways.

Mounting evidence suggests that these non-classical B cell functions are critical in the manifestation of several autoimmune diseases. For example, Shlomchik and colleagues demonstrated that, in lupus-prone MRL/lpr mice, elimination of B cells results in a complete abrogation of nephritis, vasculitis, and skin disease [12]. Furthermore, MRL/lpr mice with B cells that cannot secrete Abs still develop nephritis and vasculitis. Therefore, these results suggest that, independent of autoantibody production, B cells are essential for disease initiation or progression through either APC function or secretion of proinflammatory cytokines [12].

Clinically, this has been demonstrated by the efficacy of B cell-depletion therapy in a variety of diseases. B cell-depletion therapy using the anti-CD20 monoclonal $\mathrm{Ab}$ (mAb) Rituximab is beneficial not only in autoantibody-mediated diseases but also in other diseases that are not considered to be mediated by Abs, such as type I diabetes and multiple sclerosis. Thus, B cells have additional functions outside of Ab production, and are likely to play significant roles in autoimmunity.

\section{The history of regulatory $B$ cells}

While B-cell functions mentioned above work to augment immune responses, recent studies have highlighted the importance of a "new" B cell population, called regulatory B cells, that suppresses immune responses. In fact, evidence for the suppressive function of B cells was first documented more than 30 years ago. In 1974, Katz, et al. demonstrated that column depletion of B cells from splenocyte preparations eliminated the ability of adoptively transferred cell preparations to inhibit DTH responses in guinea pigs [1]. This finding led to the conclusion that DTH responses and T-cell function can be regulated by "suppressor B cells" that are distinct from Ab-producing cells. Follow-up studies showed that adoptive transfer of Ag-activated B cells or B-cell blasts could induce tolerance in recipient naive mice and induce the differentiation of 
suppressor T cells [13-15]. In 1983, Kennedy and Thomas, using adoptive transfer of dinitrophenyl-human immunoglobulin (DNP-HGG)- primed splenocytes, described the differentiation of Ag-specific regulatory B cells able to ablate a secondary anti-hapten immune response [16].

Despite the availability of these data in the literature, the suppressive role of B cells in immune regulation was mostly overlooked for another decade. Subsequently, a B cells regulatory effect in autoimmune diseases was reported by Wolf, Janeway, and colleagues in 1996 [17]. They observed that B cell-deficient $\mu$ MT mice, immunized with myelin basic protein (MBP) peptide in complete Freund's adjuvant (CFA), suffer a much more severe form of experimental autoimmune encephalomyelitis (EAE) than wild type mice and do not undergo spontaneous remission. Fillatreau, Anderson, and colleagues later demonstrated that the exacerbation of EAE in $\mu \mathrm{MT}$ mice is due to a deficiency in IL-10-producing B cells [18]. Mizoguchi and Bhan, however, were the first to use the term 'regulatory B cells' to designate B cells with inhibitory properties [2, 19]. They reported that, in T-cell receptor (TCR) $\alpha$-deficient mice, which spontaneously develop colitis, B-cell deficiency results in an earlier onset of disease and exacerbated intestinal inflammation. While they first proposed an Ab-mediated protective mechanism since they observed that administration of purified immunoglobulin (Ig) from TCR $\alpha$-deficient mice attenuated colitis in TCR $\alpha$-deficient $\mu \mathrm{MT}$ mice, they later demonstrated that regulatory $\mathrm{B}$ cells differentiate in a chronic inflammatory environment express high levels of CD1d, produce IL-10, and suppress the progression of intestinal inflammation by directly downregulating inflammatory cascades associated with IL-1 $\beta$ and STAT3 activation. Mauri et al. also demonstrated a suppressive function for IL 10-producing B cells in collagen-induced arthritis (CIA) [20]. Thus, regulatory B cells are now considered key regulators of many disease states due to their production of IL-10. 


\section{The characterization of IL-10-producing regulatory B cells}

While earlier studies hypothesized that the suppressive function of regulatory B cells is mediated by "neutralizing” Abs, most recent studies are in agreement that this function requires IL-10. Thus, in order to characterize regulatory B cells, which B cell subsets secret IL-10 is a critical question. IL-10 production is a well-known property of peritoneal B-1 cells. Almost 20 years ago, O’Garra and colleagues demonstrated that peritoneal $\mathrm{CD}^{+} \mathrm{B}$ cells preferentially produce IL-10 transcripts in response to lipopolysaccharide (LPS) stimulation [21, 22]. Among conventional B-2 cells, MZ B cells have been found to produce elevated levels of IL-10 upon LPS or CpG stimulation $[23,24]$. In addition, ligation of CD1d, highly expressed on MZ B cells, induces IL-10 secretion by some cell types [25].

In 2002, Mizoguchi et al. reported that CD1d ${ }^{\text {hi }} C D 21{ }^{\text {int }} C D 23{ }^{\text {hi }} \operatorname{IgM}^{\text {int }} B$ cells are induced in mesenteric lymph nodes in the TCR $\alpha$-deficient colitis mouse model [19]. Inflamed mesenteric lymph node B cells demonstrated IL-10-dependent regulatory properties, although individual IL-10-producing B-cell phenotypes were not identified.

In 2007, using CD19-deficient mice, we found that B cells are important for suppressing contact hypersensitivity (CHS)-induced inflammation [26]. CD19 is a positive B-cell response regulator which governs intrinsic and stimulant-dependent signaling thresholds in B cells $[8,27,28]$. CD19 is a member of the Ig superfamily and is expressed only on B cells and follicular DCs. CD19 functions as a specialized adapter protein regulating Src-family protein tyrosine kinases, PI3K, and Vav, and thus serves as a key regulator of multiple signaling pathways that are crucial for modulating basal and BCR-induced signals. Although B cells from CD19-deficient mice are hyposensitive to a variety of transmembrane signals, CD19 loss results in increased and prolonged reactivity of CHS, which is ameliorated by the adoptive transfer of $\mathrm{CD} 21^{\text {hi }} \mathrm{CD} 23^{\mathrm{lo}} \mathrm{MZ}$ B cells from wild type mice [26]. Subsequently, it has been demonstrated that regulatory

B cells are predominantly contained within a phenotypically unique CD1 $\mathrm{d}^{\text {hi }} \mathrm{CD}^{+}$subset 
in the spleens of naive wild-type mice [29]. Tedder and colleagues termed this specific subset of regulatory B cells "B10 cells" to highlight that these rare CD1d $\mathrm{d}^{\text {hi }} \mathrm{CD} 5^{+} \mathrm{B}$ cells only produce IL-10, are responsible for most IL-10 production by B cells, and to distinguish them from other regulatory B-cell subsets that may also exist. B10 cells share overlapping phenotypic markers with $\mathrm{CD}^{+} \mathrm{B}-1 \mathrm{a}$ cells,

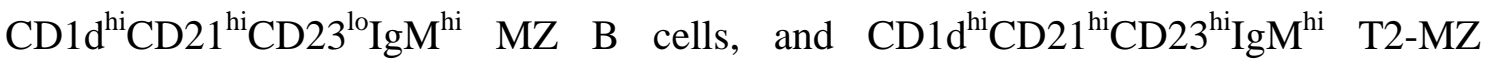
precursor (MZP) B cells, but do not exclusively belong to either subset. Additionally, B10 cells are quite reminiscent of a dendritic cell-like B-cell subset identified by Burke and colleagues in 2004 [30]. These cells display a phenotype of B220 ${ }^{+} \mathrm{CD} 1 \mathrm{~d}^{+} \mathrm{CD}^{\mathrm{lo} /{ }^{+}} \mathrm{CD} 19^{+} \mathrm{CD} 11 \mathrm{c}^{-} \mathrm{CD} 24^{\mathrm{hi}} \mathrm{CD} 21 / 35^{+} \operatorname{IgM}^{+} \operatorname{IgD}^{\text {low }} \mathrm{CD} 43^{+} \mathrm{CD} 44^{\text {hi }}$, secret IL-10 in response to culture with Chlamydia trachomatis, and function as APCs for cellular immune responses. In 2007, Mauri and colleagues [31] reported that IL-10 cells that can prevent CIA development when adoptively transferred express a $\mathrm{CD}_{21}{ }^{\text {hi }} \mathrm{CD} 23^{+}$IgM $^{\text {hi }} \mathrm{CD} 1 \mathrm{~d}^{\text {hi }} \mathrm{CD} 93^{\text {int }}$ phenotype, which is similar to that of T2-MZP B cells. Thus, regulatory B cells or IL-10-producing B cells described in each of the studies share many, if not all, phenotypic markers.

\section{Regulatory B cells in disease states}

Studies have elucidated critical roles for regulatory B cells in various murine disease models. This review focuses on skin and connective tissue diseases including CHS, arthritis, and lupus. Other organ-specific autoimmune disease models, especially EAE $[17,18,32,33]$ and colitis [19, 34], have also provided important mechanisms for how regulatory B cells work, as have been reviewed in several recent, outstanding review articles [2-5].

\section{5-1. Contact hypersensitivity}


CHS has been considered as a prototypic Th1 cell-mediated inflammatory reaction where B cells are not involved in Ag presentation and thereby have a minimum role, if any, in augmenting inflammation. However, we have found that the CHS response is significantly exacerbated in CD19-deficient mice where it was expected that B-cell hyporesponsiveness would reduce CHS responses (Figure 2) [26]. This led to the hypothesis that CD19-defienct mice are defective in regulatory B cells. Indeed, the transfer of MZ B cells from wild type mice normalized the augmented CHS in CD19-deficient mice. Therefore, while CD19 is a positive regulator in B cell responses, the positive regulation provided by CD19 expression is also critical in the regulatory B cell subset, and CD19 loss results in a defect in regulatory B cells. These studies were extended by showing reduced CHS responses in human CD19 transgenic (hCD19Tg) mice that overexpress CD19 and enhanced CHS in wild type mice in which all B cells were depleted using CD20 mAbs [29]. The findings that B cells from CD19-deficient mice are defective in IL-10 production whereas B cells from hCD19Tg mice overproduce IL-10 have led to the identification of the IL-10-producing B cell subset responsible for CHS suppression. This splenic B cell subset display CD1d ${ }^{\text {hi }} \mathrm{CD}^{+}$ phenotype, as described above. Importantly, IL-10-deficient mice also possess the $\mathrm{CD}^{\mathrm{hi}} \mathrm{CD5}^{+} \mathrm{B}$ cell population, although the adoptive transfer of IL-10-deficient CD1 $\mathrm{d}^{\text {hi }} \mathrm{CD}^{+}$B cells does not ameliorate CHS responses, suggesting that this suppression is IL-10-dependent.

B-1 cells in the peritoneal cavity have long been known to be a rich source of IL-10, and are also likely to play a role in the suppression of CHS, particularly in the late phase [35]. CD22-deficient mice exhibit delayed recovery from CHS reactions compared with wild type mice. Adoptive transfer of wild type peritoneal B-1 cells, but not IL-10-deifcient peritoneal B-1 cells, reverses the prolonged CHS reaction seen in CD22-deificient mice as well as CD19-deficient mice (Figure 2), and this is blocked by the simultaneous injection with IL-10 receptor Ab. Thus, two distinct regulatory B cell 
subsets cooperatively inhibit CHS responses. While splenic CD1d ${ }^{\mathrm{hi}} \mathrm{CD} 5^{+} \mathrm{B}$ cells have a crucial role in suppressing the acute exacerbating phase of CHS, peritoneal B-1a cells are likely to suppress the late remission phase, although their role appears less significant compared with that of splenic B10 cells. CD22 deficiency may result in disturbed CHS remission by impaired retention or survival of peritoneal B-1a cells that migrate into lymphoid organs.

The role of B-1 cells in CHS is still controversial, however. While our study, as described above [35], suggests that B-1 cells have a protective role, Tsuji and colleagues demonstrate a promoting, rather than inhibitory, role for peritoneal B-1 cells in CHS [36]. Using Btk-defective xid mice on a CBA background, they demonstrated that Ag-specific IgM Abs from peritoneal B-1 cells are required for the recruitment of effector T cells in the early elicitation phase [36]. The discrepancy between these results may be due to the differences in mouse genetic backgrounds and/or haptens. Also, it is possible that peritoneal B-1 cells have both promoting and suppressive roles in CHS.

Ultraviolet (UV) exposure is known to suppress a wide variety of immune reactions including CHS, and may do so, in part, through activation of regulatory $\mathrm{B}$ cells. Matsumura et al. reported that transferring lymph nodes cells from UV-irradiated, FITC-sensitized mice into normal recipients induces immune tolerance [37]. Notably, the cell responsible is an $\mathrm{FITC}^{+} \mathrm{CD}_{19}{ }^{+} \mathrm{B} 220^{+}$IL-10-secreting B cell. In this study, platelet-activating factor and serotonin were found to be necessary for the activation of immunoregulatory B cells [37]. These findings are supported by the data from Byrne and Halliday, who report that UV exposure activates B cells that suppress APC function [38].

\section{5-2. Arthritis}

B cells are considered pathogenic in rheumatoid arthritis (RA). While the precise mechanisms of B cell-mediated pathogenesis of human RA remain unclear, B 
cell-depletion therapy using Rituximab has been shown to be effective. B cells are also important for initiating inflammation in mouse RA models. Mathis, Benoist, and colleagues have established the $\mathrm{K} / \mathrm{BxN}$ mouse model, in which a disease with most of the clinical, histologic, and immunologic features of RA spontaneously develops due to the secretion of arthritogenic Ig, However, they also observed that B cell-deficient mice injected with arthritogenic Ig develop more severe arthritis, suggesting that B cells may have an inhibitory effect [39]. Mauri and colleagues have demonstrated a protective role for B cells in CIA, in addition to their previously known pathogenic role [20]. They have shown that when arthritogenic B cells are stimulated with anti-CD40 mAb and collagen they produce IL-10, and that B cells stimulated with anti-CD40 mAb and collagen from arthritogenic mice, when adoptively transfered into syngeneic immunized recipient mice, prevented the induction of arthritis and ameliorated established disease. This regulatory function of B cells depends on the production of IL-10, as transfer of T2-MZP B cells isolated from IL-10-deficient DBA mice fail to protect recipient mice from developing arthritis [31]. IL-10-producing B cells display a CD1d ${ }^{\text {hi }} \mathrm{CD} 21^{\text {hi }} \mathrm{CD} 23^{+} \operatorname{IgM}^{+}$phenotype, which is consistent with T2-MZP B cells. The numbers of IL-10-producing T2-MZP B cells, present in naïve mouse spleens, decrease at the peak of inflammation and increase during the remission phase of CIA. The adoptive transfer of T2-MZP B cells, but not follicular B cells or MZ B cells, derived from arthritogenic mice in remission phase, prevented CIA and reduced disease severity. Moreover, the adoptive transfer of T2-MZP B cells from naive mice also had a significant but less dramatic effect on CIA progression.

Another study demonstrated that administering apoptotic thymocytes to mice before the clinical onset of CIA is protective for joint inflammation and bone destruction [40]. Activated splenic B cells responded directly to apoptotic cell treatment by increasing secretion of IL-10, which is important for inducing T-cell-derived IL-10. Moreover, the passive transfer of B cells from apoptotic cell-treated mice provided 
significant protection from arthritis. Inhibition of IL-10 in vivo reversed the beneficial effects of apoptotic cell treatment. Thus, apoptotic cells can induce regulatory B cells, which, in turn, are able to influence the cytokine profile of collagen-specific effector $\mathrm{T}$ cells.

\section{5-3. Lupus}

B cells play several critical roles in the pathogenesis of systemic lupus erythematosus (SLE). In lupus, it is now apparent that regulatory B cells are important for the disease suppression (Figure 3). We have examined the role of regulatory B cells in the New Zealand Black and New Zealand White F1 hybrid (NZB/W) mouse model [41]. In NZB/W mice deficient for CD19 the emergence of anti-nuclear Abs was significantly delayed compared with wild type NZB/W mice. However, the pathologic manifestations of nephritis appeared significantly earlier, and survival was considerably reduced in CD19-deficient NZB/W mice compared with wild type mice. These results demonstrate both disease-promoting and protective roles for B cells in lupus pathogenesis. In wild type NZB/W mice, the $\mathrm{CD} 1 \mathrm{~d}^{\mathrm{hi}} \mathrm{CD} 5^{+} \mathrm{B} 220^{+} \mathrm{B}$ cell subset that includes B10 cells was increased by 2.5-fold during the disease course, whereas CD19-deficient NZB/W mice lacked this $\mathrm{CD} 1 \mathrm{~d}^{\mathrm{hi}} \mathrm{CD}^{+}$regulatory B cell subset. Furthermore, the transfer of splenic CD1 $\mathrm{d}^{\text {hi }} \mathrm{CD}^{+}$B cells from wild type NZB/W mice into CD19-deficient NZB/W recipients significantly prolonged their survival. Intriguingly, regulatory $\mathrm{T}$ cells were significantly decreased in CD19-deficient NZB/W mice, and the transfer of wild type CD1 $\mathrm{d}^{\text {hi }} \mathrm{CD}^{+} \mathrm{B}$ cells induced T regulatory cell expansion in CD19-deficient NZB/W mice. Thus, regulatory B10 cells play an important protective role in lupus.

That distinct B cell populations have opposing protective and pathogenic roles during lupus progression is directly shown by our experiments in which CD20 mAb treatment initiated in 12-28-week-old NZB/W F1 mice, and administered every 4 weeks thereafter, significantly delays spontaneous disease [42]. By contrast, B cell 
depletion initiated in 4-week-old mice hastens disease onset. This is especially important when considering the efficacy of B cell-targeted therapy in lupus since pan-B-cell depletion therapies may be a double-edged sword for some patients.

Mauri and colleagues, using MLR/lpr mice, demonstrated that transfer of in vitro anti-CD40-generated T2 MZP B cells significantly improves renal disease and survival by an IL-10-dependent mechanism, while transfer of unmanipulated T2 B cells, isolated from mice with established lupus, are not able to confer protection to diseased mice [43]. Anti-CD40-treated T2 MZP B cells accumulate in the spleen after transfer, and induce the differentiation of $\mathrm{IL}-10^{+} \mathrm{CD} 4^{+} \mathrm{T}$ cells. In addition, in vivo administration of agonistic anti-CD40 Ab halts and reverses established lupus. Collectively, these studies demonstrate the importance of protective role for regulatory B cells in lupus.

\section{Regulatory B cells in humans}

In comparison to the accumulation of data relating to mouse regulatory B cells, little is known regarding human regulatory B cells. However, it has been demonstrated that human B cells can produce IL-10 [44]. Human tonsil B cells costimulated with CpG ODNs and CD40 ligand (CD40L) have a high proliferative response and produce large quantities of IL-10. Interestingly, CD40 activation of human B cells associated with TLR stimulation promotes the production of IL-10 [45]. Peripheral blood B cells from patients with SLE, RA, and primary Sjögren Syndrome transcribe constitutively higher levels of messenger RNA for IL-10 as compared with controls [46]. Another study showed that peripheral blood B cells from SLE patients constitutively secrete more IL-10 in vitro than those from normal controls on both a per-cell and a percentage basis. This production of IL-10 is associated with expression of CD40L, suggesting that cellular activation is a prerequisite for the production of IL-10 [47]. While CD5 ${ }^{+} \mathrm{B}$ cells from SLE patients are reported to produce high levels of IL-10 [48], contrasting data show that IL-10-producing B cells in SLE do not belong to the CD5 population, but 
rather, to a population of activated $\mathrm{CD} 40 \mathrm{~L}^{+} \mathrm{B}$ cells [47].

Recently, Blair et al. have demonstrated that human $\mathrm{CD} 19^{+} \mathrm{CD} 24^{\mathrm{hi}} \mathrm{CD} 38^{\mathrm{hi}} \mathrm{B}$ cells possess regulatory capacity [49]. After CD40 stimulation, CD19 ${ }^{+}$CD2 $4{ }^{\text {hi }}$ CD $38{ }^{\text {hi }} B$ cells suppressed the differentiation of Th1 cells, partially via the provision of IL-10, but not transforming growth factor- $\beta$ (TGF- $\beta$ ), and their suppressive capacity was reversed by the addition of CD80 and CD86 mAbs. In addition, CD19 ${ }^{+}$DD24 $4^{\text {hi }}$ CD38 ${ }^{\text {hi }}$ B cells isolated from the peripheral blood of SLE patients were refractory to further CD40 stimulation, produced less IL-10, and lacked the suppressive capacity of their healthy counterparts. Interestingly, their study suggests that, in contrast to murine regulatory B cells, the suppressive activity of human regulatory B cells is only partially dependent on IL-10. One possibility is cell-cell contact, in which interactions between B cells and $\mathrm{CD}^{+} \mathrm{T}$ cells mediated through CD80/CD86 and CD28/CTLA-4 may work synergistically with B cell IL-10 production to suppress $\mathrm{CD}^{+} \mathrm{T}$ cell cytokine production. By contrast, Tedder and colleagues consider that B10 and progenitor B10 cells are predominantly found within the $\mathrm{CD} 24^{\mathrm{hi}} \mathrm{CD} 27^{+}$B cell subpopulation (Dr. Thomas F. Tedder, personal communication). Thus, it is highly likely that regulatory B cells also exist in humans, while the cell-surface phenotype of regulatory B cells is yet to reach consensus.

Finally, B cell-depletion therapy also suggests the existence of regulatory B cells in humans and their relevance to skin diseases. Recent reports describe patients who developed psoriasis following treatment with rituximab for rheumatoid arthritis [50]. While this is not definitive evidence for their existence, it is intriguing to speculate that regulatory B cells may be involved in a variety of skin and connective tissue diseases in human other that those described above.

While the importance of regulatory $\mathrm{B}$ cells is emerging, many questions remain. Identifying the definitive markers of regulatory B cells and clarifying the 
molecular mechanisms by which regulatory B cells suppress immune responses will be of great benefit in the development of new B cell-targeted therapeutic strategies. 


\section{References}

1 Katz, S. I., Parker, D. and Turk, J. L., B-cell suppression of delayed hypersensitivity reactions. Nature 1974. 251: 550-551.

2 Mizoguchi, A. and Bhan, A. K., A case for regulatory B cells. J Immunol 2006. 176: 705-710.

3 Fillatreau, S., Gray, D. and Anderton, S. M., Not always the bad guys: B cells as regulators of autoimmune pathology. Nat Rev Immunol 2008. 8: 391-397.

4 Mauri, C. and Ehrenstein, M. R., The 'short' history of regulatory B cells. Trends Immunol 2008. 29: 34-40.

5 DiLillo, D. J., Matsushita, T. and Tedder, T. F., B10 cells and regulatory B cells balance immune responses during inflammation, autoimmunity, and cancer. Ann N Y Acad Sci 2010. 1183: 38-57.

6 Martin, F. and Chan, A. C., B cell immunobiology in disease: evolving concepts from the clinic. Annu Rev Immunol 2006. 24: 467-496.

7 Browning, J. L., B cells move to centre stage: novel opportunities for autoimmune disease treatment. Nat Rev Drug Discov 2006. 5: 564-576.

8 Fujimoto, M. and Sato, S., B cell signaling and autoimmune diseases: CD19/CD22 loop as a B cell signaling device to regulate the balance of autoimmunity. J Dermatol Sci 2007. 46: 1-9.

9 Yanaba, K., Bouaziz, J. D., Matsushita, T., Magro, C. M., St Clair, E. W. and Tedder, T. F., B-lymphocyte contributions to human autoimmune disease. Immunol Rev 2008. 223: 284-299.

10 Lund, F. E., Garvy, B. A., Randall, T. D. and Harris, D. P., Regulatory roles for cytokine-producing B cells in infection and autoimmune disease. Curr Dir Autoimmun 2005. 8: 25-54.

11 Harris, D. P., Haynes, L., Sayles, P. C., Duso, D. K., Eaton, S. M., Lepak, N. M., Johnson, L. L., Swain, S. L. and Lund, F. E., Reciprocal regulation of polarized cytokine production by effector B and T cells. Nat Immunol 2000. 1: 475-482.

12 Shlomchik, M. J., Craft, J. E. and Mamula, M. J., From T to B and back again: positive feedback in systemic autoimmune disease. Nature Rev Immunol 2001. 1: 147-153.

13 L'Age-Stehr, J., Teichmann, H., Gershon, R. K. and Cantor, H., Stimulation of 
regulatory $\mathrm{T}$ cell circuits by immunoglobulin-dependent structures on activated B cells. Eur J Immunol 1980. 10: 21-26.

14 Shimamura, T., Hashimoto, K. and Sasaki, S., Feedback suppression of the immune response in vivo. I. Immune B cells induce antigen-specific suppressor T cells. Cell Immunol 1982. 68: 104-113.

15 Shimamura, T., Habu, S., Hashimoto, K. and Sasaki, S., Feedback suppression of the immune response in vivo. III. Lyt-1+ B cells are suppressor-inducer cells. Cell Immunol 1984. 83: 221-224.

16 Kennedy, M. W. and Thomas, D. B., A regulatory role for the memory B cell as suppressor-inducer of feedback control. J Exp Med 1983. 157: 547-558.

17 Wolf, S. D., Dittel, B. N., Hardardottir, F. and Janeway, C. A., Jr., Experimental autoimmune encephalomyelitis induction in genetically B cell-deficient mice. $J$ Exp Med 1996. 184: 2271-2278.

18 Fillatreau, S., Sweenie, C. H., McGeachy, M. J., Gray, D. and Anderton, S. M., B cells regulate autoimmunity by provision of IL-10. Nat Immunol 2002. 3: 944-950.

19 Mizoguchi, A., Mizoguchi, E., Takedatsu, H., Blumberg, R. S. and Bhan, A. K., Chronic intestinal inflammatory condition generates IL-10-producing regulatory B cell subset characterized by CD1d upregulation. Immunity 2002. 16: 219-230.

20 Mauri, C., Gray, D., Mushtaq, N. and Londei, M., Prevention of arthritis by interleukin 10-producing B cells. J Exp Med 2003. 197: 489-501.

21 O'Garra, A., Chang, R., Go, N., Hastings, R., Haughton, G. and Howard, M., Ly-1 B (B-1) cells are the main source of B cell-derived interleukin 10. Eur J Immunol 1992. 22: 711-717.

22 O'Garra, A., Stapleton, G., Dhar, V., Pearce, M., Schumacher, J., Rugo, H., Barbis, D., Stall, A., Cupp, J., Moore, K. and et al., Production of cytokines by mouse B cells: B lymphomas and normal B cells produce interleukin 10. Int Immunol 1990. 2: 821-832.

23 Dalwadi, H., Wei, B., Schrage, M., Spicher, K., Su, T. T., Birnbaumer, L., Rawlings, D. J. and Braun, J., B cell developmental requirement for the G alpha i2 gene. J Immunol 2003. 170: 1707-1715.

24 Brummel, R. and Lenert, P., Activation of marginal zone B cells from lupus mice with type A(D) CpG-oligodeoxynucleotides. J Immunol 2005. 174: 
2429-2434.

25 Colgan, S. P., Hershberg, R. M., Furuta, G. T. and Blumberg, R. S., Ligation of intestinal epithelial CD1d induces bioactive IL-10: critical role of the cytoplasmic tail in autocrine signaling. Proc Natl Acad Sci U S A 1999. 96: 13938-13943.

26 Watanabe, R., Fujimoto, M., Ishiura, N., Kuwano, Y., Nakashima, H., Yazawa, N., Okochi, H., Sato, S., Tedder, T. F. and Tamaki, K., CD19 expression in B cells is important for suppression of contact hypersensitivity. Am J Pathol 2007. 171: 560-570.

27 Tedder, T. F., Poe, J. C., Fujimoto, M., Haas, K. M. and Sato, S., The CD19-CD21 signal transduction complex of B lymphocytes regulates the balance between health and autoimmune disease: systemic sclerosis as a model system. Curr Dir Autoimmun 2005. 8: 55-90.

28 Ishiura, N., Nakashima, H., Watanabe, R., Kuwano, Y., Adachi, T., Takahashi, Y., Tsubata, T., Okochi, H., Tamaki, K., Tedder, T. F. and Fujimoto, M., Differential phosphorylation of functional tyrosines in CD19 modulates B-lymphocyte activation. Eur J Immunol 2010. 40: 1192-1204.

29 Yanaba, K., Bouaziz, J. D., Haas, K. M., Poe, J. C., Fujimoto, M. and Tedder, T. F., A regulatory B cell subset with a unique $\mathrm{CD} 1 \mathrm{~d}^{\text {hi }} \mathrm{CD}^{+}$phenotype controls $\mathrm{T}$ cell-dependent inflammatory responses. Immunity 2008. 28: 639-650.

30 Burke, F., Stagg, A. J., Bedford, P. A., English, N. and Knight, S. C., IL-10-producing B220+CD11c- APC in mouse spleen. J Immunol 2004. 173: 2362-2372.

31 Evans, J. G., Chavez-Rueda, K. A., Eddaoudi, A., Meyer-Bahlburg, A., Rawlings, D. J., Ehrenstein, M. R. and Mauri, C., Novel suppressive function of transitional 2 B cells in experimental arthritis. J Immunol 2007. 178: 7868-7878.

32 Matsushita, T., Yanaba, K., Bouaziz, J. D., Fujimoto, M. and Tedder, T. F., Regulatory B cells inhibit EAE initiation in mice while other B cells promote disease progression. J Clin Invest 2008. 118: 3420-3430.

33 Lampropoulou, V., Hoehlig, K., Roch, T., Neves, P., Calderon Gomez, E., Sweenie, C. H., Hao, Y., Freitas, A. A., Steinhoff, U., Anderton, S. M. and Fillatreau, S., TLR-activated B cells suppress T cell-mediated autoimmunity. $J$ Immunol 2008. 180: 4763-4773. 
34 Shimomura, Y., Mizoguchi, E., Sugimoto, K., Kibe, R., Benno, Y., Mizoguchi, A. and Bhan, A. K., Regulatory role of B-1 B cells in chronic colitis. Int Immunol 2008. 20: 729-737.

35 Nakashima, H., Hamaguchi, Y., Watanabe, R., Ishiura, N., Kuwano, Y., Okochi, H., Takahashi, Y., Tamaki, K., Sato, S., Tedder, T. F. and Fujimoto, M., CD22 expression mediates the regulatory functions of peritoneal B-1a cells during the remission phase of contact hypersensitivity reactions. J Immunol 2010. 184: 4637-4645.

36 Tsuji, R. F., Szczepanik, M., Kawikova, I., Paliwal, V., Campos, R. A., Itakura, A., Akahira-Azuma, M., Baumgarth, N., Herzenberg, L. A. and Askenase, P. W., $\mathrm{B}$ cell-dependent $\mathrm{T}$ cell responses: IgM antibodies are required to elicit contact sensitivity. J Exp Med 2002. 196: 1277-1290.

37 Matsumura, Y., Byrne, S. N., Nghiem, D. X., Miyahara, Y. and Ullrich, S. E., A role for inflammatory mediators in the induction of immunoregulatory B cells. $J$ Immunol 2006. 177: 4810-4817.

38 Byrne, S. N. and Halliday, G. M., B cells activated in lymph nodes in response to ultraviolet irradiation or by interleukin-10 inhibit dendritic cell induction of immunity. J Invest Dermatol 2005. 124: 570-578.

39 Korganow, A. S., Ji, H., Mangialaio, S., Duchatelle, V., Pelanda, R., Martin, T., Degott, C., Kikutani, H., Rajewsky, K., Pasquali, J. L., Benoist, C. and Mathis, D., From systemic T cell self-reactivity to organ-specific autoimmune disease via immunoglobulins. Immunity 1999. 10: 451-461.

40 Gray, M., Miles, K., Salter, D., Gray, D. and Savill, J., Apoptotic cells protect mice from autoimmune inflammation by the induction of regulatory B cells. Proc Natl Acad Sci U S A 2007. 104: 14080-14085.

41 Watanabe, R., Ishiura, N., Nakashima, H., Kuwano, Y., Okochi, H., Tamaki, K., Sato, S., Tedder, T. F. and Fujimoto, M., Regulatory B cells (B10 cells) have a suppressive role in murine lupus: CD19 and B10 cell deficiency exacerbates systemic autoimmunity. J Immunol 2010. 184: 4801-4809.

42 Haas, K. M., Watanabe, R., Matsushita, T., Nakashima, H., Ishiura, N., Okochi, H., Fujimoto, M. and Tedder, T. F., Protective and pathogenic roles for B cells during systemic autoimmunity in NZB/W F1 mice. J Immunol 2010. 184: 4789-4800. 
43 Blair, P. A., Chavez-Rueda, K. A., Evans, J. G., Shlomchik, M. J., Eddaoudi, A., Isenberg, D. A., Ehrenstein, M. R. and Mauri, C., Selective targeting of B cells with agonistic anti-CD40 is an efficacious strategy for the generation of induced regulatory T2-like B cells and for the suppression of lupus in MRL/lpr mice. $J$ Immunol 2009. 182: 3492-3502.

44 Jamin, C., Morva, A., Lemoine, S., Daridon, C., de Mendoza, A. R. and Youinou, P., Regulatory B lymphocytes in humans: a potential role in autoimmunity. Arthritis Rheum 2008. 58: 1900-1906.

45 Gantner, F., Hermann, P., Nakashima, K., Matsukawa, S., Sakai, K. and Bacon, K. B., CD40-dependent and -independent activation of human tonsil B cells by CpG oligodeoxynucleotides. Eur J Immunol 2003. 33: 1576-1585.

46 Llorente, L., Richaud-Patin, Y., Fior, R., Alcocer-Varela, J., Wijdenes, J., Fourrier, B. M., Galanaud, P. and Emilie, D., In vivo production of interleukin-10 by non-T cells in rheumatoid arthritis, Sjogren's syndrome, and systemic lupus erythematosus. A potential mechanism of B lymphocyte hyperactivity and autoimmunity. Arthritis Rheum 1994. 37: 1647-1655.

47 Diaz-Alderete, A., Crispin, J. C., Vargas-Rojas, M. I. and Alcocer-Varela, J., IL-10 production in B cells is confined to CD154+ cells in patients with systemic lupus erythematosus. J Autoimmun 2004. 23: 379-383.

48 Amel Kashipaz, M. R., Huggins, M. L., Lanyon, P., Robins, A., Powell, R. J. and Todd, I., Assessment of Be1 and Be2 cells in systemic lupus erythematosus indicates elevated interleukin-10 producing CD5+ B cells. Lupus 2003. 12: 356-363.

49 Blair, P. A., Norena, L. Y., Flores-Borja, F., Rawlings, D. J., Isenberg, D. A., Ehrenstein, M. R. and Mauri, C., CD19(+)CD24(hi)CD38(hi) B cells exhibit regulatory capacity in healthy individuals but are functionally impaired in systemic Lupus Erythematosus patients. Immunity 2010. 32: 129-140.

50 Dass, S., Vital, E. M. and Emery, P., Development of psoriasis after B cell depletion with rituximab. Arthritis Rheum 2007. 56: 2715-2718. 


\section{Figure legends}

Figure 1. Development and phenotypic markers of B-2 cell lineage in mouse

Figure 2. Two regulatory B cell subsets suppress contact hypersensitivity (CHS).

(A) Wild type and CD19-deficient (CD19 $9^{--}$) mice were sensitized with $0.5 \%$ DNFB for 2 consecutive days. Five days later, CHS was elicited by $0.25 \%$ DNFB on the right ear. Ear thickness was measured on the day of challenge and for 10 days post challenge. (B) Splenic follicular B cells (yellow bars), sera (green bars), splenic marginal zone B cells including B10 cells (red bars), or peritoneal B-1 cells (blue bars) from wild type mice were transferred to CD19-/- mice. CHS was elicited by DNFB 1 day after transfer. *, $P<0.05, * *, P<0.01$.

Figure 3. Pathogenic and protective roles of B cells in systemic lupus erythematosus (SLE).

B cells have pathogenic roles in SLE via autoantibody production, cytokine secretion, and antigen presentation. On the other hand, regulatory B cells exert a protective activity via IL-10 production, which may affect regulatory T cell functions. 


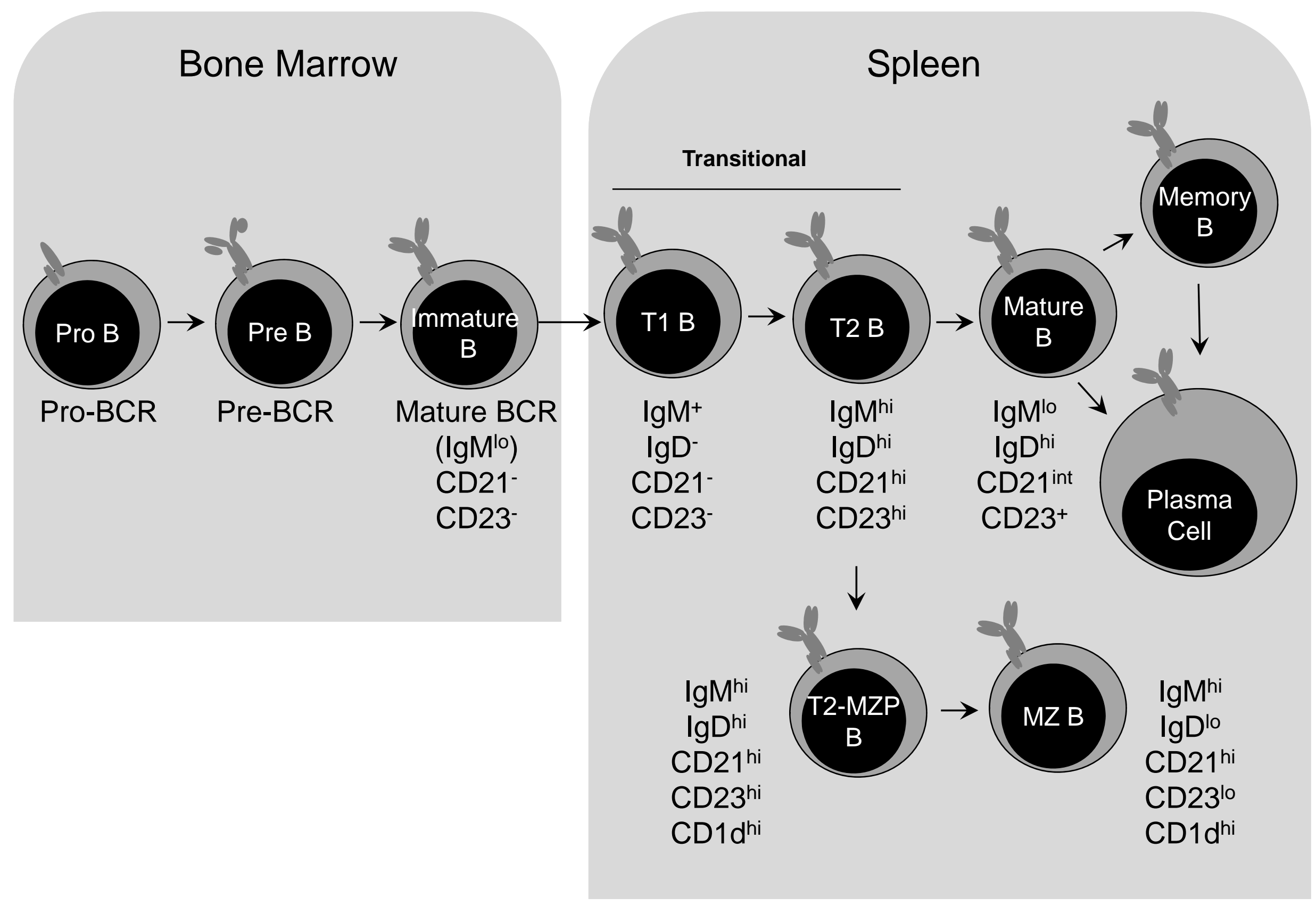




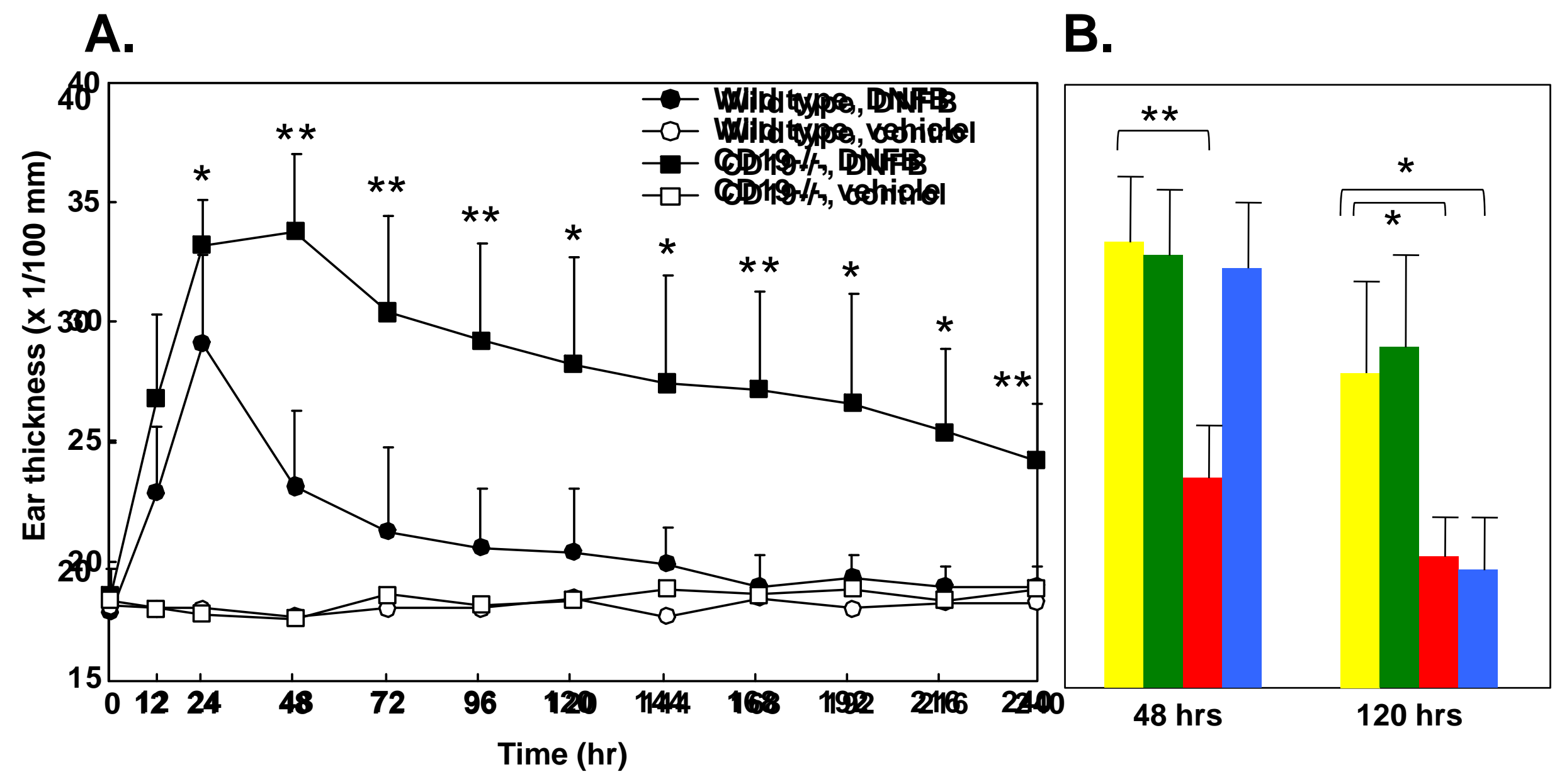



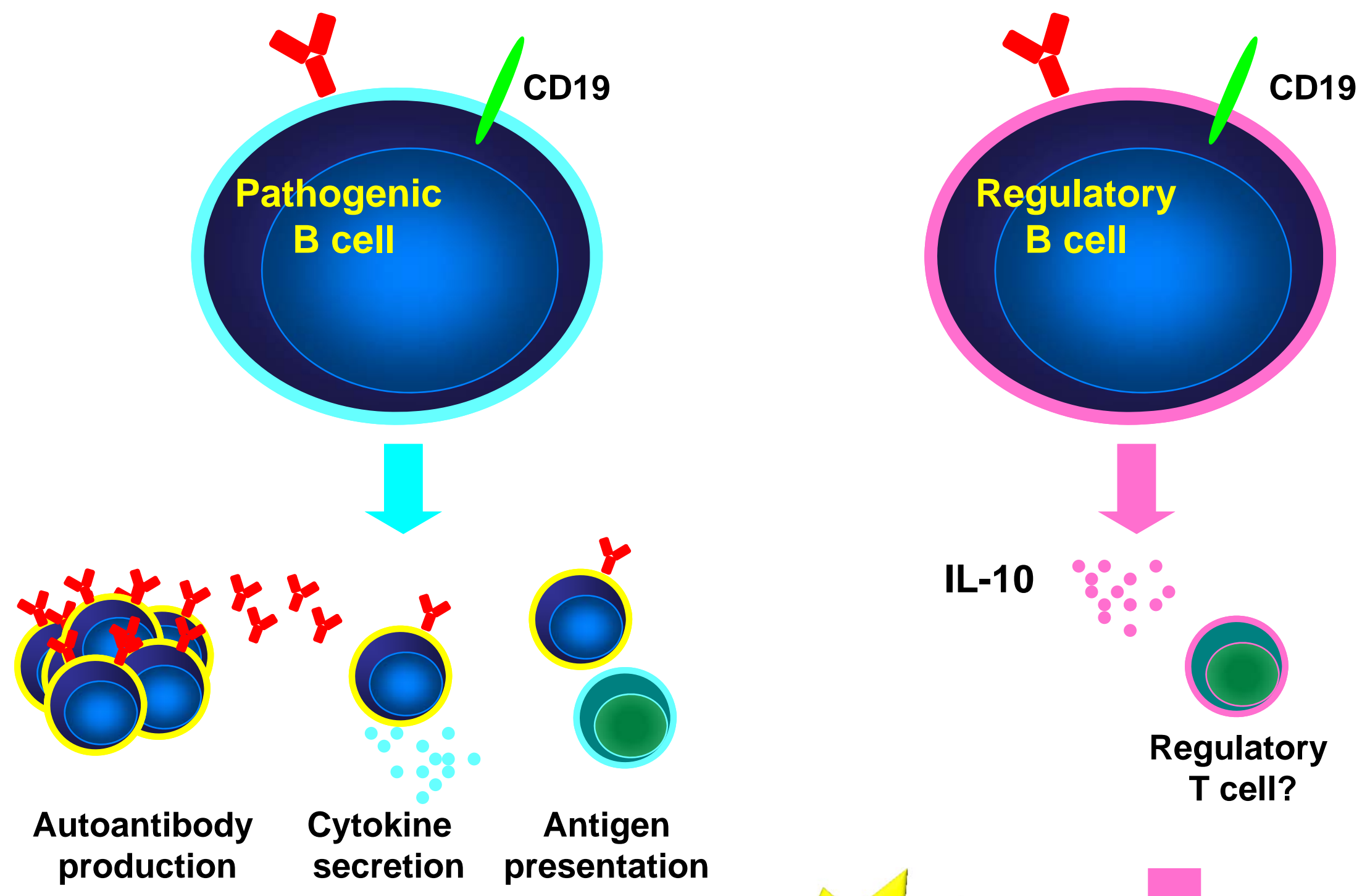

IL-10

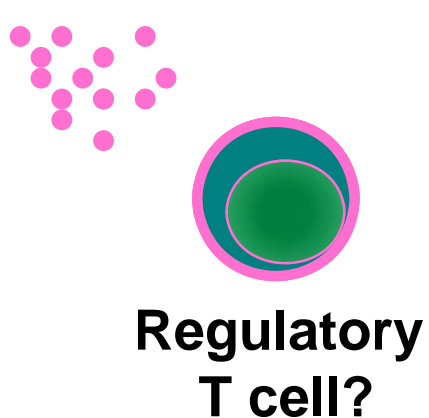

production

secretion presentation

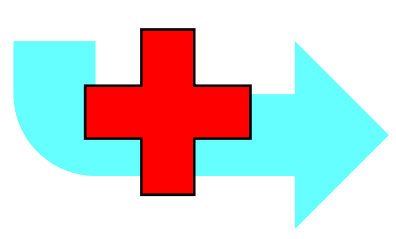

